\title{
Trends and Disparities in Breast Cancer Incidence-Mortality Rates of Black-White Women in the U.S.: 2000-2016
}

\author{
Ishrat Binte Aftab ${ }^{1}$, Akash Ahmed ${ }^{2}$, Sinthia Kabir Mumu ${ }^{3}$, \\ Tonima Fairooz Mouly², Drishti Sharad Commar ${ }^{4}$
}

${ }^{1}$ Department of Sports and Health Science, Technical University of Munich, Munich, Germany

${ }^{2}$ Department of Mathematics and Natural Sciences, BRAC University, Dhaka, Bangladesh

${ }^{3}$ Department of Biology, Purdue University Fort Wayne, Fort Wayne, USA

${ }^{4}$ Department of Medical Informatics, Deggendorf Institute of Technology, Deggendorf, Germany

Email: *ishrat.aftab@tum.de, akash.ahmed@bracu.ac.bd, mumusk01@pfw.edu, mouly96@gmail.com,dcommar@gmail.com

How to cite this paper: Aftab, I.B., Ahmed, A., Mumu, S.K., Mouly, T.F. and Commar, D.S. (2021) Trends and Disparities in Breast Cancer Incidence-Mortality Rates of BlackWhite Women in the U.S.: 2000-2016. Advances in Breast Cancer Research, 10, 200217.

https://doi.org/10.4236/abcr.2021.104017

Received: July 1, 2021

Accepted: October 8, 2021

Published: October 11, 2021

Copyright $\odot 2021$ by author(s) and Scientific Research Publishing Inc. This work is licensed under the Creative Commons Attribution International License (CC BY 4.0).

http://creativecommons.org/licenses/by/4.0/

\begin{abstract}
Introduction: Female Breast cancer is the second leading cause of cancer-related deaths in the U.S. While the incidence rate is lower in Hispanic-Black, the mortality rate is higher compared to Non-Hispanic White. This study investigates the trends of incidence and mortality rate of breast cancer in the U.S.: 2000-2016. It further explores the racial disparities between these two races. Method: Data for four age groups (15 - 39 yrs, 40 - 64 yrs, 65 - 74 yrs, 75+ yrs) of Hispanic-Black and Non-Hispanic White women for breast cancer were extracted from SEER; age-adjusted rate (U.S. 2000 standard population). Primary trend analysis was done with PyCharm 2020.3.3. (line charts) and regression models to check any significant increase or decrease over the years were done with JoinPoint 4.8.0.1 (APC, 95\% CI, significant p-value: $<0.05)$. Result: Incidence rate is higher in Non-Hispanic White women, whereas mortality rate is higher in Hispanic Black. The $40-64$ yrs age groups showed an increase in incidence rate for Hispanic Black women, whereas an decrease for White women. The least vulnerable group, 15 - 39 yrs age showed an increase in incidence rate in Non-Hispanic White women. The mortality rate was declining overall for both races. Conclusion: Disparities in oncologic healthcare, insurance system and socio-economic factors are possibly responsible for the higher mortality in Black American women. Improvements in these factors may reduce racial differences.
\end{abstract}

\section{Keywords}

Black, White, Non-Hispanic White, Cancer, Breast, SEER, Incidence, Mortality, 
Race/Ethnicity, United States

\section{Introduction}

Breast cancer affects more than 1 in 10 million women globally [1]. The global cancer report 2018 of the International Agency for Research on Cancer (IARC) states female breast cancer is 1 of the top 3 cancer types worldwide with an estimation of 2.1 million new cases in 2018 [2]. It is the most common human neoplasm, responsible for $27 \%$ of cancers in developed countries [3]. In the United States, breast cancer is the second leading cause of mortality [1]. According to the Center for Prevention and Disease (CDC), 245,299 new cases of female breast cancer with 41,487 death occurred in this region in 2016 [4]. The Breast Cancer organization statistics of U.S. estimation postulates, about 1 in 8 women (about 12\%) in the U.S. will develop invasive breast cancer in their lifetime [5]. Conversely, 1 in 39 women will die from breast cancer in the U.S. [6]. Surveillance, Epidemiology and End Results (SEER) program estimates almost 268,600 new cases of breast cancer to be diagnosed in the U.S. in 2019 [7].

Breast cancer occurs when an abnormal growth of cells is observed in any components of the breast, although this occurs most commonly in the lobules [8]. Different studies have categorized breast cancer in different ways and the most common is to classify it into two: 1) Invasive breast cancer and 2) Non-invasive breast cancer (in-situ). Multiple studies showed that major a portion of breast cancer type consists of invasive type carcinoma [8]. Invasive Ductal Carcinoma (IDC) is the most frequent type of $\mathrm{BC}$ globally which consists of $50 \%-75 \%$ of all female breast cancers [9]. For non-invasive BC, Ductal Carcinoma In-Situ (DCIS) is prominent. DCIS is basically a neoplastic proliferation of epithelial cells which is limited to the ducts or lobules [10].

Racial disparity is high in the U.S. which makes it as one of the major contributing factors in breast cancer mortality in this region. By 2019, roughly $14 \%$ of the country's population was Black (includes Hispanic) [11]. The South has the biggest concentration of Black people in the United States. More than half of the population (56\%) lives there, with 17 percent in the Midwest, 17 percent in the Northeast, and 10 percent in the West [11]. The incidence and mortality rate of female breast cancer differ considerably by race/ethnicity and Black and Non-Hispanic White (from now referred to as "White") women have higher rates of incidence and mortality rate than other races [12]. Typically, Black women are diagnosed with breast cancer at a younger age compared to White women [13]. Even though the incidence rate is lower for African American women (126.7 vs 130.8 ), the mortality rate is significantly higher (28.4 vs 20.3 ) in them [14]. Overall, the mortality rate is $40 \%$ higher for Black women [14]. This high incidence rate in White women and high mortality rate in Black women in the United States is a result of multiple factors. Dietary fat intake is strongly related to BC 
outcomes. Black women are often diagnosed with advanced stage of breast cancer where they cannot get stage-specific treatment anymore. Different studies have demonstrated physical activity is associated with lowering the risk factor of BC [15]. Compared to other races, African Americans (part of the Hispanic Black) are more likely to be overweight, obese, and have higher BMI and waist-tohip ratios as they take less part in physical exercise [15]. In addition to that, they usually receive less from the recommended screenings [16]. The underlying reason behind this disparity is multilayered and multifaceted. Studies suggest that this effect of race on the stage of cancer is related to numerous socioeconomic factors such as education, income, insurance status, etc [17] [18].

To explore these disparities this study characterizes breast cancer patients in four different age groups from young to an older age. Approximately $99.3 \%$ and $71.2 \%$ of all breast cancer-associated deaths in the U.S. were reported in women over the age of 40 and 60, consecutively [19]. Also, more than $40 \%$ of their breast cancer patients are $65+$ years which basically accounts for almost $60 \%$ of total deaths of cancer [20] [21]. According to National Cancer Institute (NIH) the breast cancer risk in the next 10 years for 30 years old is $0.48 \%$ whereas this risk is $4.07 \%$ for 70 years old people [22]. There are several hypotheses behind this risk factor. The phenotype of breast cancer-prone women is the result of genomic instability, telomeric dysfunction or DNA damage-all of which is higher with ageing [23]. Adult women have a higher risk of mitotic divisions of adult tissue stem which is related to developing cancer [24]. Genetic instability which is associated with damaged DNA repair capacity is highly related to cancer development [25].

Compared to any other country, racial disparities are more evident in the U.S. due to the huge Black population. Multiple studies have investigated the trend of incidence and mortality rate over the years. However, they focused on a time frame before the millennium and the effect of race in this time frame was not explored. A recent study has observed the trend of breast cancer in the U.S. over 2000-2015 but the outcome of the study is incidence and survival of young breast cancer patients (20 - $49 \mathrm{yrs)}$ whereas mortality rate is utterly important to explore especially in old age group [26]. Therefore, very less is known about the patterns of breast cancer incidence and mortality rate in terms of racial disparities in the U.S. For this reason, it is important to analyze the data to explore how these patterns are changing and distinguish the determinants of a higher mortality rate of breast cancer in Black women despite having a lower incidence rate than White women. This study is set to understand how racial disparity is affecting the incidence and mortality rate of female breast cancer patients $(>15$ yrs) in these two races of the United States from 2000 to 2016. Figuring out the significant changing year and understanding the reason behind it may lead us to further improvement for the better treatment of underprivileged races. This may also contribute to planning effective strategies of survival, screening management, assessment, and community service planning and policy improvement for 
preventing this crisis.

\section{Methods}

\subsection{Data Source}

This study obtained data from Surveillance, Epidemiology and End Results (SEER) program. The data was extracted in July 2019. It provides rates per 100,000 and are age-adjusted to the 2000 U.S. Std Population (19 age groups-Census P25-1130; Supplementary Table 1 and Table 2; available online). It collects data from 21 areas of the United States [27].

As breast cancer is very rare in young age, four different age groups (15 - 39 yrs, 40 - 64 yrs, 65 - 74 yrs, 75+ yrs) were selected for data extraction. All data was not available for Asian/Pacific Islander and American Indian/Alaska Native, thus these races were excluded. Besides, Black-White population has higher incidence rate in the U.S. than any other race in breast cancer, therefore, data for these two races were included by using SEER explorer.

\subsection{Statistical Analysis}

SEER explorer was used to extract incidence and mortality rate data of four age groups for Black and White women in the United States. Review managers 5.3 were used to calculate the standard error. To observe general trends over the years (descriptive analysis) PyCharm 2020.3.3 was used for creating line charts. JoinPoint Regression Program version 4.8.0.1 was used to check for significant decrease or increase in rates (inferential analysis). This program used t-distribution and normal $(\mathrm{z})$ distribution depending on the JoinPoint segment number.

\section{Results}

Hispanic-Black women had higher mortality rate in all age groups (Figures 1(e)-(h)) despite having lower incidence rate overall except for 15 - 39 yrs age group (Figure 1(a)). The incidence and mortality rate were high in older age groups (Figure 1).

\section{Incidence Rate}

The overall incidence rate was higher in White women, except for 15 - 39 yrs age group. The youngest age group, 15 - 39 yrs, showed a non-stable trend in descriptive analysis (Figure 1). However, in JoinPoint regression model, this age group showed significant increase for White but not for Black (Table 1). In the 40 - 64 yrs age group, rate was higher in White in comparison with Black (Figure 1). The gap between rates for this age group was getting narrowed within two races as the rate was increasing for Black and decreasing in White (Figure 2, Table 1). The 65 - 74 yrs age group had a higher rate in White than Black (Figure 1). This rate dropped significantly in 2000-2004 for White, increased significantly in 2004-2009 for Black (Figure 2, Table 1). The oldest age group, $75+$ yrs showed non-stable trend over the years in Black. The regression 
(a)

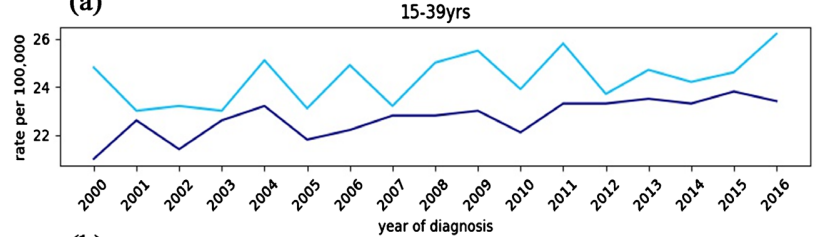

(b)

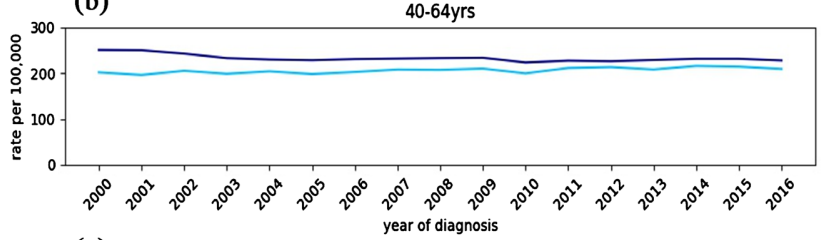

(c)

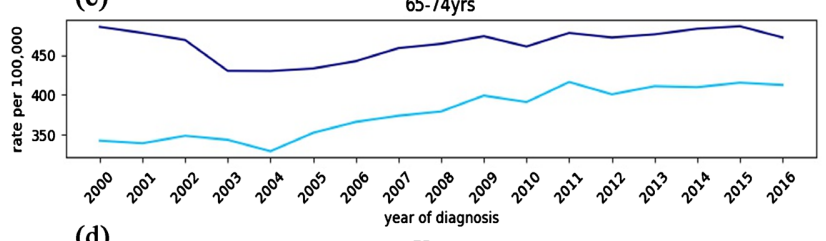

(d)

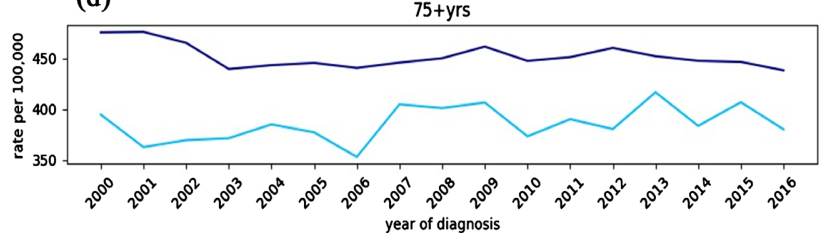

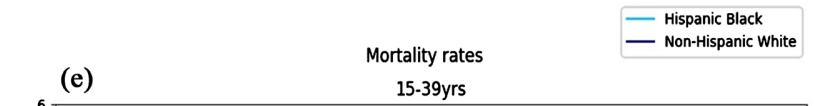
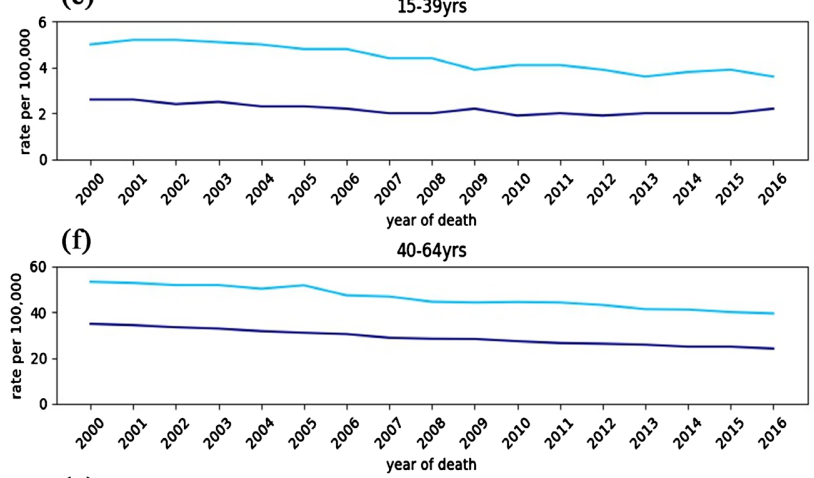

(g)

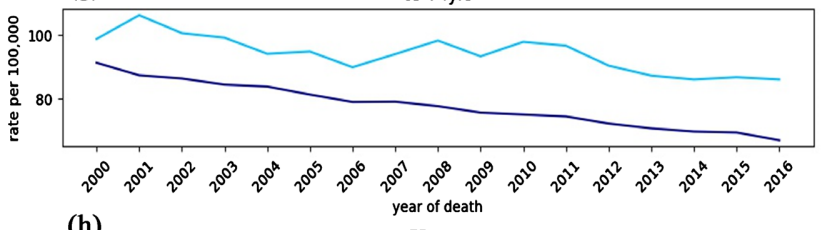

(h)

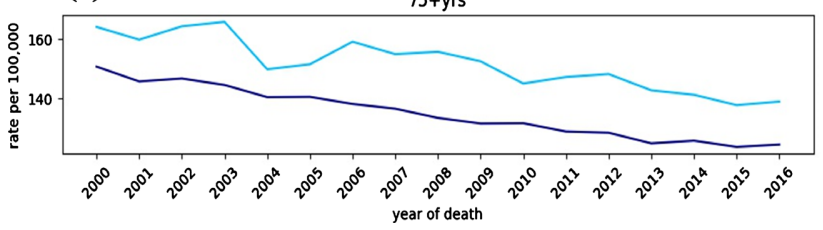

Figure 1. Trends of breast cancer incidence and mortality rate of Hispanic-Black and Non-Hispanic White women of the United States; 2000-2016, SEER 21 registries. Rates are illustrated for four age groups (15 - 39 yrs, 40 - 64 yrs, 65 - 74 yrs, $75+$ yrs). Chart (a)-(d) is showing trends for breast cancer incidence rate in 15 - 39 yrs, 40 - 64 yrs, 65 - 74 yrs and 75+ yrs respectively. Chart (e)-(h) is showing trends for breast cancer mortality rate in 15 - 39 yrs, 40-64yrs, 65 - 74 yrs and 75+ yrs respectively.

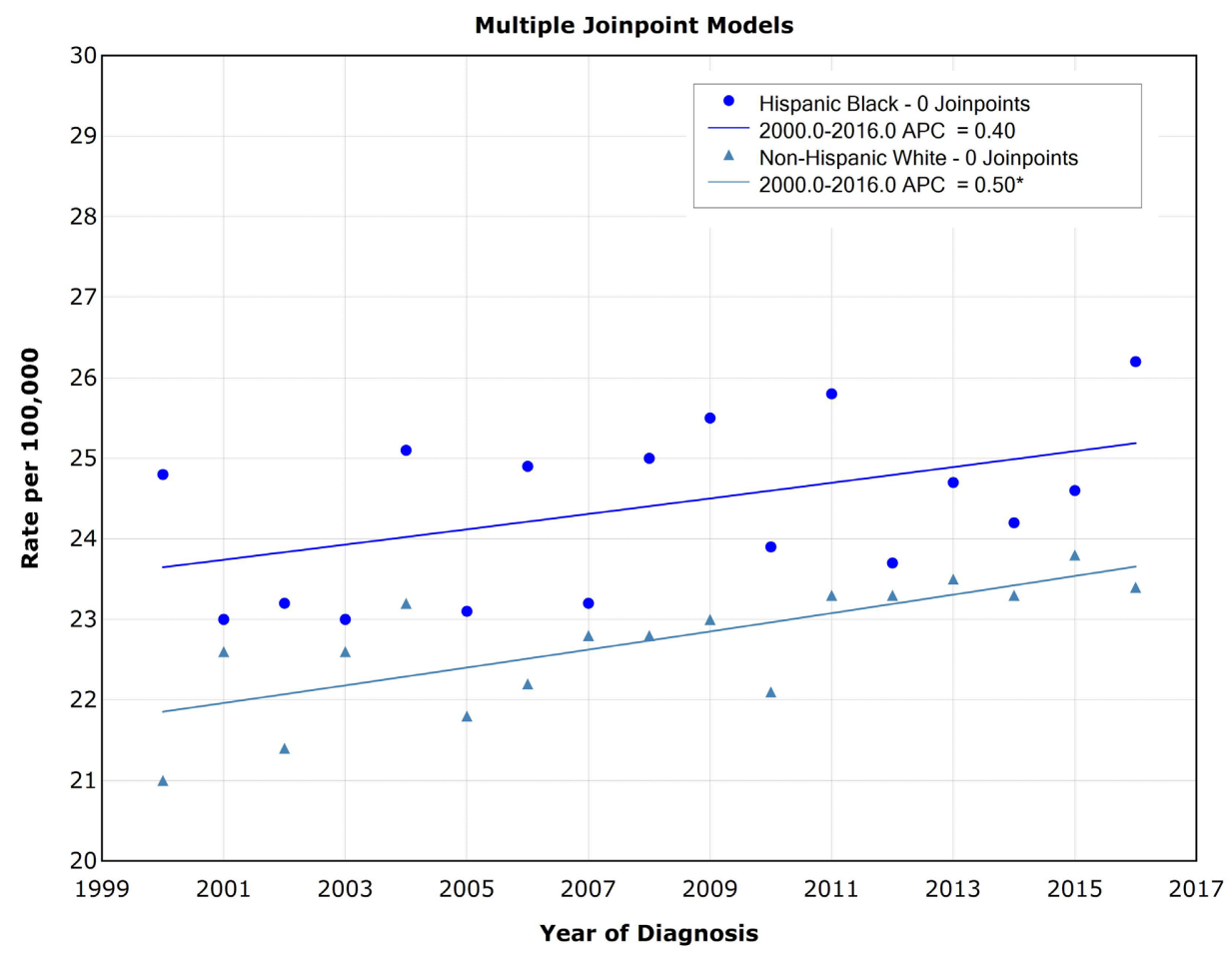

(a) 


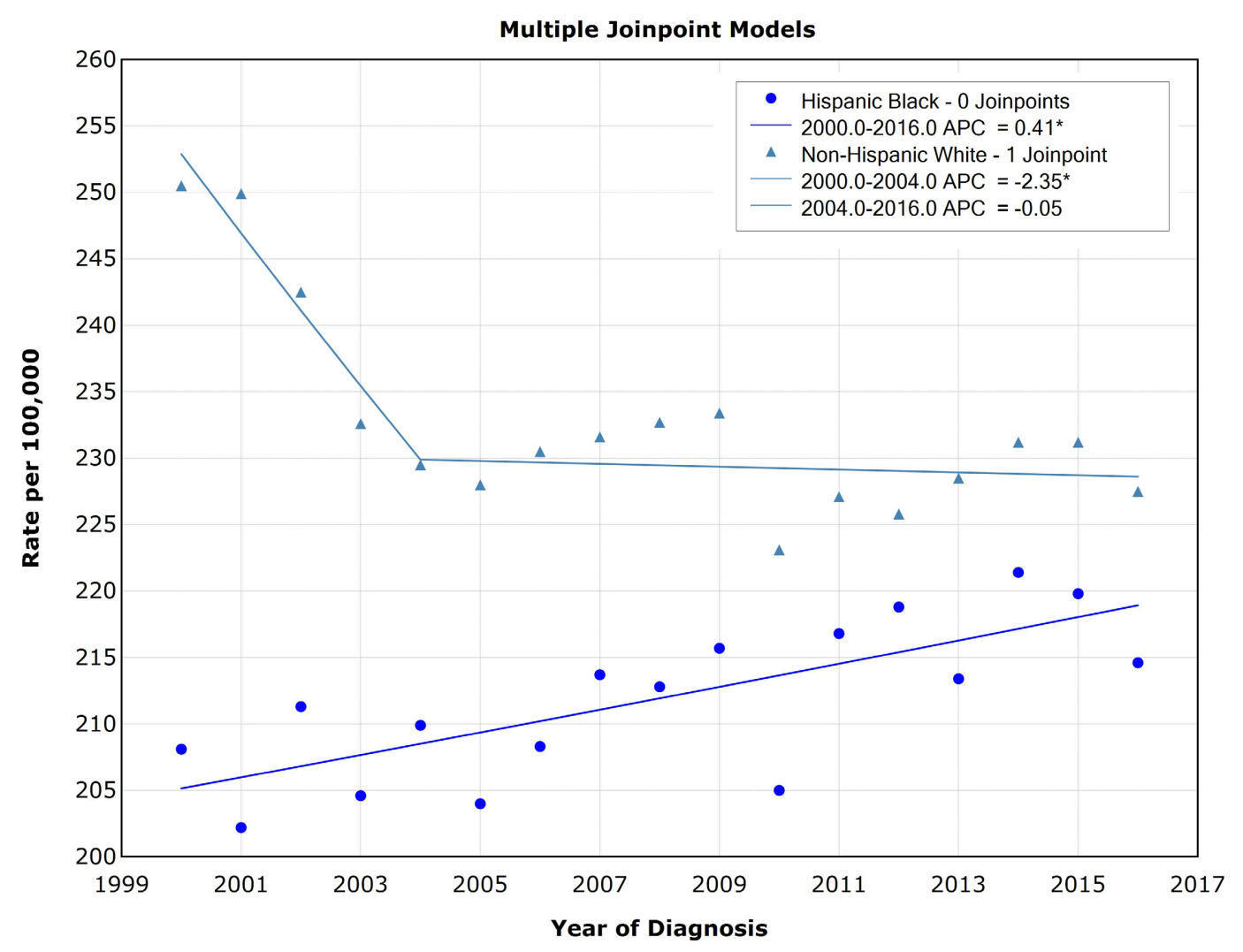

(b)

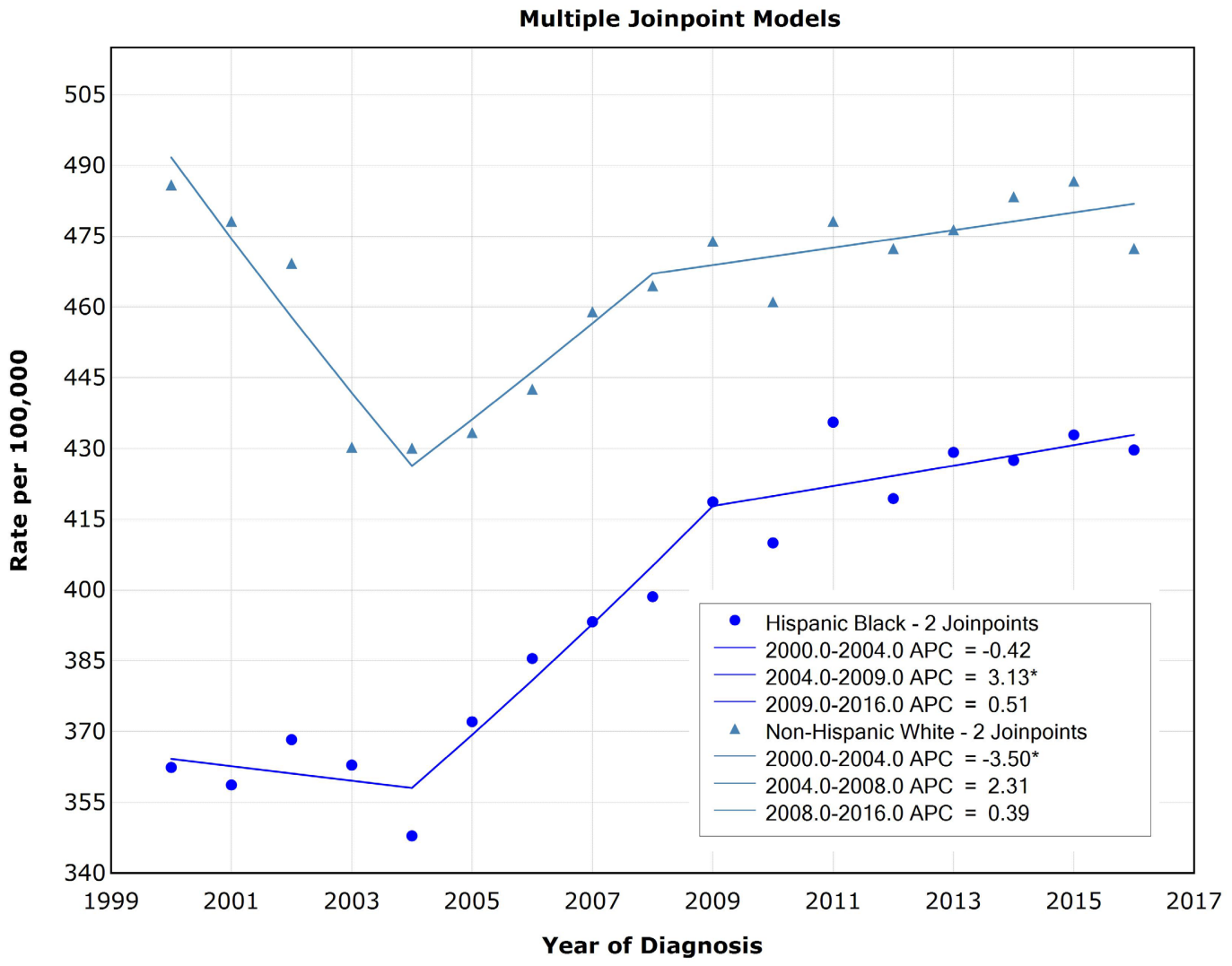

(c) 


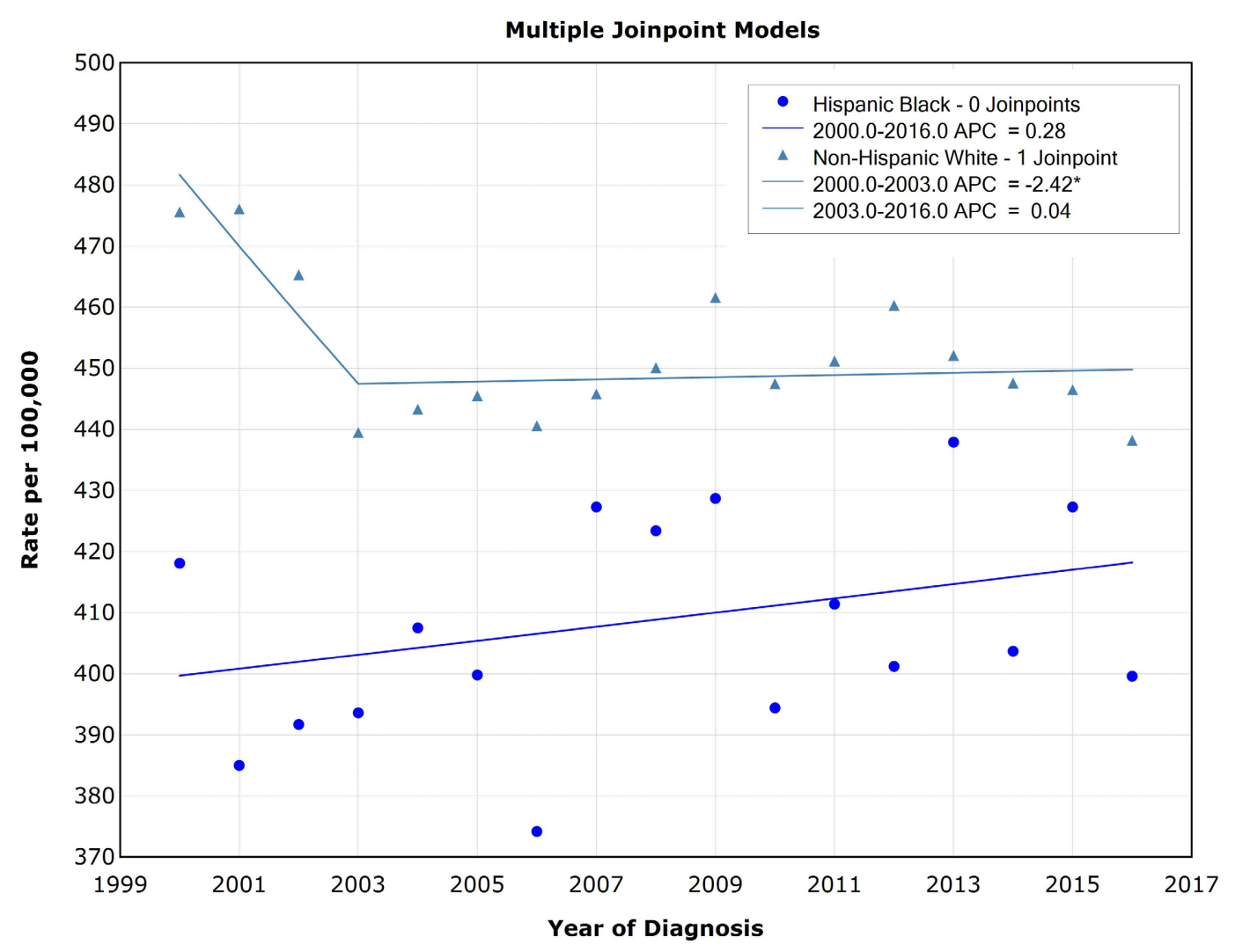

(d)

Figure 2. JoinPoint regression model of breast cancer incidence rate for Hispanic-Black and Non-Hispanic White women of the United States; 2000-2016, SEER 21 registries. Analysis is done for four age groups (15 - 39 yrs, 40 - 64 yrs, 65 - 74 yrs, 75+ yrs). Model A, B, C \& D is showing JoinPoint regression model for breast cancer incidence rate in 15 - 39 yrs, 40 - 64 yrs, 65 - 74 yrs and 75+ yrs respectively. (a) 15 - 39 yrs; (b) 40 - 64 yrs; (c) 65 - 74 yrs; (d) 75+ yrs.

Table 1. Annual percentage change and p-value of Hispanic-Black and Non-Hispanic White women incidence rate in the United States, 2000-2016; extracted from JoinPoint regression model.

\begin{tabular}{|c|c|c|c|c|c|c|}
\hline \multicolumn{7}{|c|}{ Incidence Rate } \\
\hline \multirow{2}{*}{ Age Group } & \multicolumn{3}{|c|}{ Hispanic Black } & \multicolumn{3}{|c|}{ Non-Hispanic White } \\
\hline & Year & $\operatorname{APC}(95 \% \mathrm{CI})$ & P-Value & Year & $\operatorname{APC}(95 \% \mathrm{CI})$ & P-Value \\
\hline $15-39 \mathrm{yrs}$ & $2000-2016$ & 0.40 & 0.05 & $2000-2016$ & $0.50^{*}$ & $0.0007^{* *}$ \\
\hline \multirow[t]{2}{*}{$40-64 \mathrm{yrs}$} & $2000-2016$ & $0.41^{*}$ & $0.0006^{* *}$ & $2000-2004$ & $-2.35^{*}$ & $0.001^{* *}$ \\
\hline & & & & 2004-2016 & -0.05 & 0.70 \\
\hline \multirow[t]{3}{*}{$65-74 \mathrm{yrs}$} & 2000-2004 & -0.42 & 0.67 & $2000-2004$ & $-3.50^{*}$ & $0.002^{* *}$ \\
\hline & 2004-2009 & $3.13^{*}$ & 0.005 & 2004-2008 & 2.31 & 0.14 \\
\hline & 2009-2016 & 0.51 & 0.09 & $2008-2016$ & 0.39 & 0.16 \\
\hline \multirow[t]{2}{*}{$75+$ yrs } & $2000-2016$ & 0.28 & 0.19 & $2000-2003$ & $-2.42^{*}$ & $0.03^{* *}$ \\
\hline & & & & 2003-2016 & 0.04 & $0.74^{*}$ \\
\hline
\end{tabular}

APC: Annual percentage change; ${ }^{\star}$ Significant increase or decrease in APC; ${ }^{*}$ Significant p-value: $<0.05$. 
model showed a significant decrease in 2000-2003 for White (Figure 2, Table 1).

\section{Mortality Rate}

The overall trend for mortality rate was decreasing over the years, as observed from descriptive analysis of the data (Figure 1). The 15 - 39 yrs showed significant drop in the rate in 2000-2012 for White and in 2000-2016 for Black women (Figure 3, Table 2). The next three age groups, 40 - 64 yrs, 65 - 74 yrs and 75+

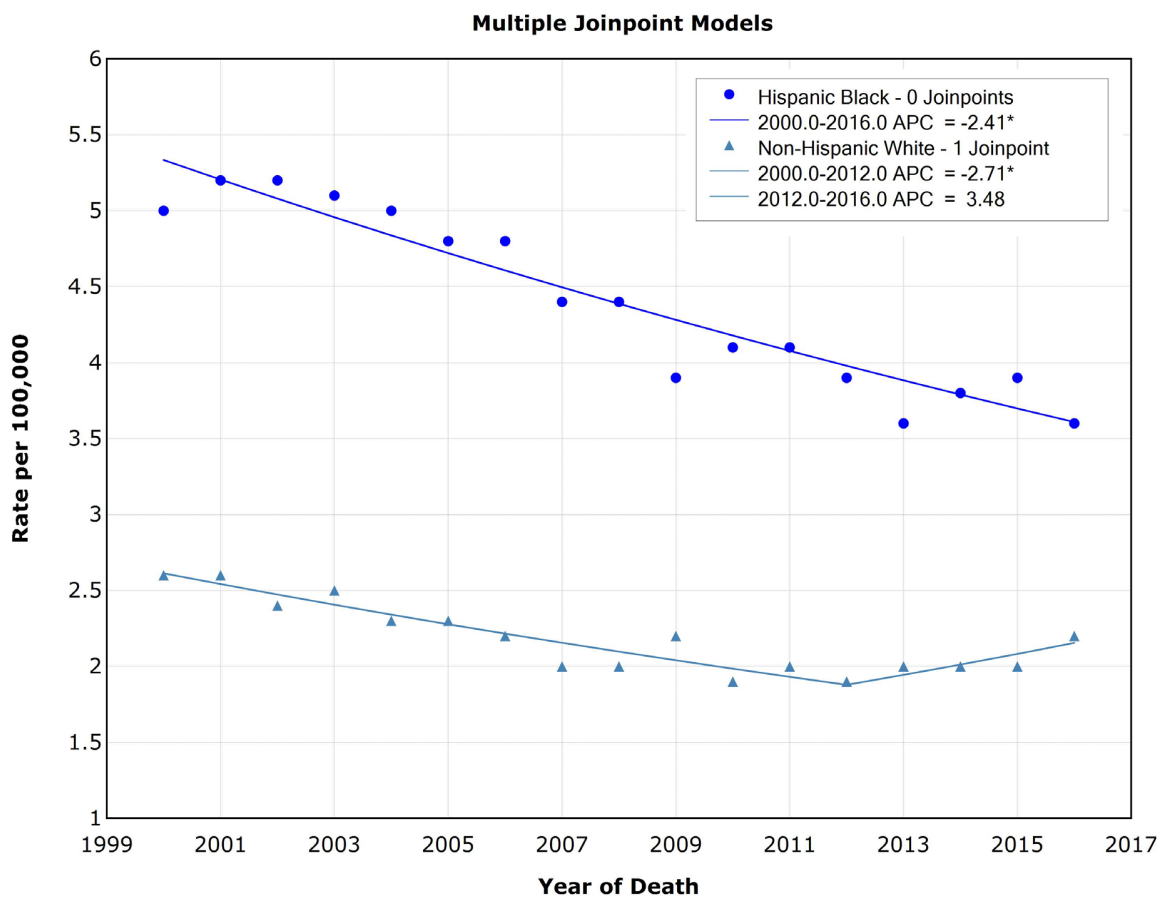

(a)

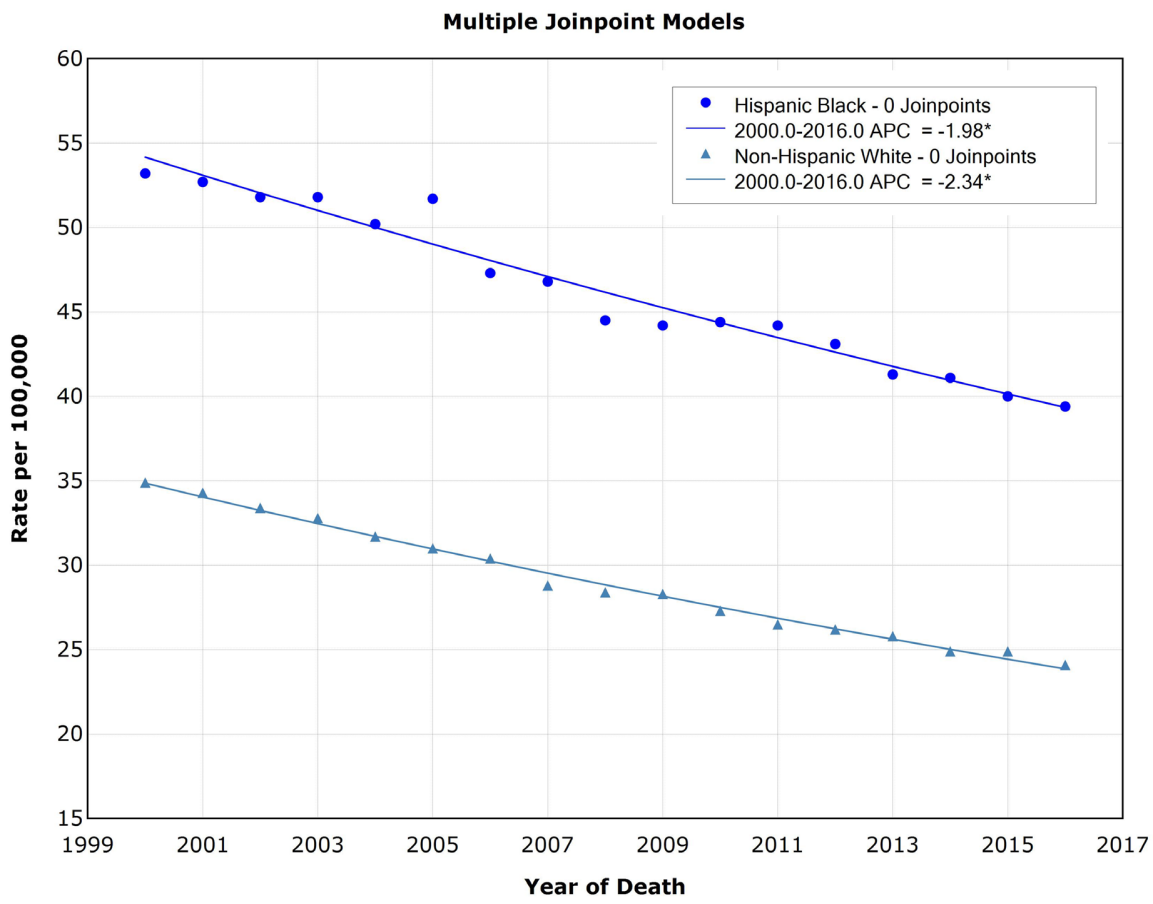

(b) 


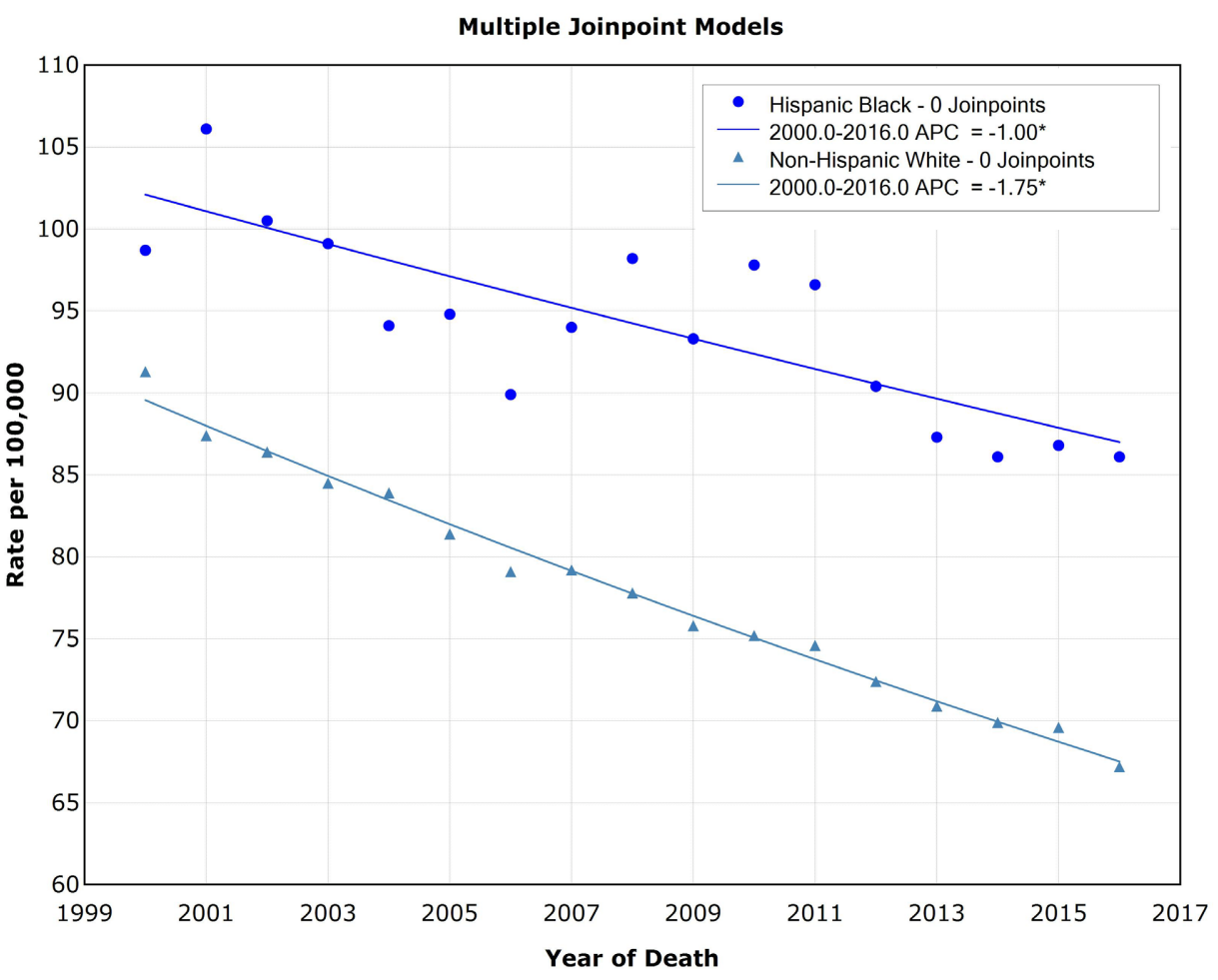

(c)

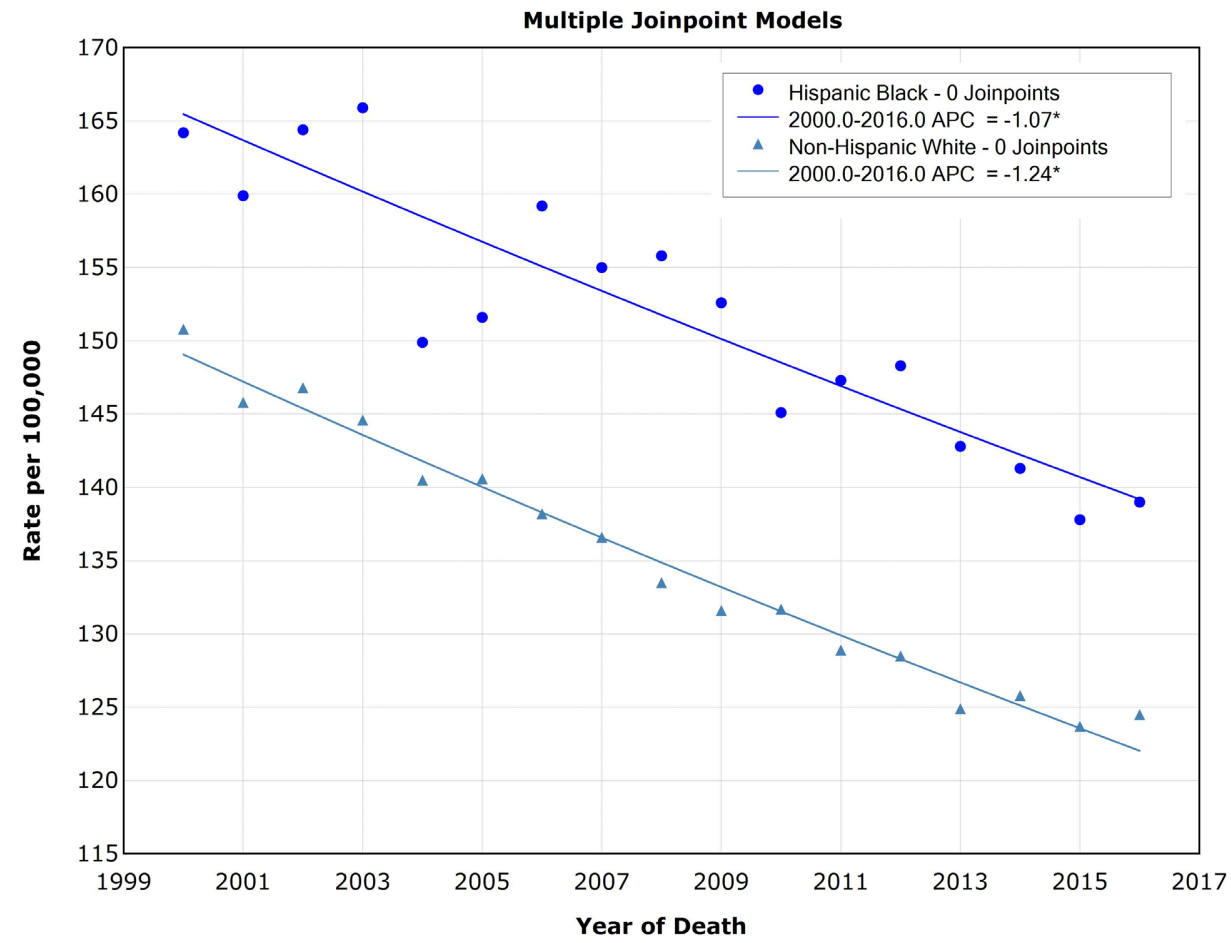

(d)

Figure 3. JoinPoint regression model of breast cancer mortality rate for Hispanic-Black and Non-Hispanic White women of the United States; 2000-2016, SEER 21 registries. Analysis is done for four age groups (15 - 39 yrs, 40 - 64 yrs, 65 - 74 yrs, 75+ yrs). Model A, B, C \& D is showing JoinPoint regression model for breast cancer mortality rate in 15 - 39 yrs, 40 - 64 yrs, 65 - 74 yrs and 75+ yrs respectively. (a) 15 - 39 yrs; (b) 40 - 64 yrs; (c) 65 - 74 yrs; (d) 75+ yrs. 
Table 2. Annual percentage change and p-value of Hispanic-Black and Non-Hispanic White women mortality rate in the United States, 2000-2016; extracted from JoinPoint regression model.

\begin{tabular}{ccccccc}
\hline \multicolumn{5}{c}{ Mortality Rate } \\
\hline \multirow{2}{*}{ Age Group } & \multicolumn{5}{c}{ Hispanic Black } & \multicolumn{3}{c}{ Non-Hispanic White } \\
\cline { 2 - 7 } & Year & APC (95\% CI) & P-Value & Year & APC (95\% CI) & P-Value \\
\hline 15 - 39 yrs & $2000-2016$ & $-2.41^{*}$ & 0.00 & $2000-2012$ & $-2.71^{*}$ & $0.000002^{* *}$ \\
& & & & $2012-2016$ & 3.48 & 0.08 \\
$40-64$ yrs & $2000-2016$ & $-1.98^{*}$ & $0.00^{* *}$ & $2000-2016$ & $-2.34^{*}$ & $0.00^{* *}$ \\
$65-74$ yrs & $2000-2016$ & $-1.00^{*}$ & $0.000062^{* *}$ & $2000-2016$ & $-1.75^{*}$ & 0.00 \\
$75+$ yrs & $2000-2016$ & $-1.07^{*}$ & 0.00 & $2000-2016$ & $-1.24^{*}$ & 0.00 \\
\hline
\end{tabular}

APC: Annual percentage change; ${ }^{*}$ Significant increase or decrease in APC; ${ }^{*}$ Significant p-value: $<0.05$.

yrs showed a significant decreasing rate from 2000-2016 for both races (Figure 3, Table 2).

\section{Discussion}

This study provides recent patterns of incidence and mortality rate of Black (includes Hispanic) and Non-Hispanic White women in the U.S. from 2000 to 2016. From descriptive analysis, a higher incidence rate was observed in White compared to Black, as illustrated (Figure 1). This finding is consistent with the CDC postulating that Black women have a lower rate of breast cancer incidence in comparison to White women between 1999 and 2013 [28]. A 2015 trend analysis of breast cancer by Carol $\mathrm{E}$ and colleagues also states that the incidence rate of breast cancer is slightly higher in White women than in Black women in the United States [12]. This slightly high incidence rate in White American women may be the result of women's age at the first childbirth. As White American women are likely to have babies at a later age than Black women, it is a risk factor for breast cancer [29]-[36]. Hormone replacement therapy (HRT) can also be associated with these higher rates. The CDC chartbook for hormone replacement therapy shows that Non-Hispanic White women used HRT more than Black women in the United States [37]. 75+ yrs age group in black women shows a fluctuating line which infers inconclusive trends over the years. The gap between incidence rates was declining for 40 - 64 yrs age group for both races over the time as the rate was increasing for Black women while decreasing in White women. The underlying reason can be early detection, awareness, and easier access to healthcare for white women and not for black women [15] [38].

From inferential analysis, a significant increase in incidence rate in the $40-64$ yrs and 65 - 74 yrs age group (2004-2009) of Black American women was observed (Figure 2, Table 1). The 15 - 39 yrs age showed a significant increase in incidence rate for White women (2000-2016) (Figure 2, Table 1). This may be associated with increasing obesity worldwide, as stated in a recent LANCET study [39]. Additionally, a significant decreasing rate was experienced in the 65 - 
74 yrs and 75+ yrs age group in 2000-2004 and 2000-2003 for both races (Figure 2, Table 1). This drop-in incidence rate can be explained by the declining prescription of HRT. In a clinical and population-based study by Clarke and colleagues, data shows that a fall exists in HRT prescription in the U.S. drastically between 2001 and 2003 [40]. This parallel decrease in HRT prescription and low incidence rate of breast cancer may have a causal relationship, as the study suggests [41].

Overall, the mortality rate was declining for breast cancer in both White and Black women in the U.S. (Figure 1). Additionally, the JoinPoint regression analysis showed a significant decrease is for both races (Figure 3, Table 2). Regression analysis showed a significant decreasing APC for three age groups (40 - 64 yrs, 65 - 74 yrs, 75+ yrs) for both races (Figure 3, Table 2). However, despite decreasing trend in the overall mortality rate and lower incidence rate, the mortality rate was substantially higher in Black women compared to White women in all age groups (Figures 1-3). This result is aligned with previous epidemiological studies and statistics. Historically Black women have a higher mortality rate than White women despite having a lower incidence rate [11]. Also, according to cancer fact sheets for African American women (Non-Hispanic) from 1990 to 2016 breast cancer death rate declined 26\% in Black women compared to a $40 \%$ decrease in White (Non-Hispanic) women [42].

The disparities between Black and White women in the United States are a result of numerous genetic and socioeconomic factors. One of the prominent genetic traits of Black women is they lack three receptors (human epidermal growth factor receptor-2, estrogen receptor and progesterone receptor) which makes them twice more likely to develop triple-negative breast cancer than any other racial groups in the U.S. [42]. This type of breast cancer has particularly adverse outcomes because of the absence of proper treatment [42]. A recent study by Huo and colleagues states that $40 \%$ of the racial variation in breast cancer subtypes is due to genetic mutation [43]. Another aggressive subtype of breast cancer, inflammatory breast cancer is also found more in Black women [44].

Furthermore, Blacks have a lower rate of estrogen receptor-positive breast cancers than Whites, which could explain racial/ethnic disparities in tamoxifen use [15]. Scientific research suggests that African Americans, who already have a greater incidence of risk factors for these disorders, may obtain less overall benefit from tamoxifen because of the increased risk of stroke, pulmonary embolism, and deep vein thrombosis associated with it [15]. Additionally, if chemoprevention is used in appropriate at-risk populations and significant modifiable risk factors including keeping a healthy weight, exercising frequently, and limiting alcohol intake are implemented, the majority of breast cancer occurrences can be avoided [15].

From a socio-economic and socio-cultural perspectives, low income, poor access to healthcare, communication barrier, poor health insurance coverage, cultural practice, and cultural beliefs towards healthcare-all are working as 
contributing factors in a higher mortality rate of Black women [45] [46]. Black women have misconceptions about surgery resulting in less limited treatment options. A recent study shows that lack of private insurance and the unfavorable tumor is responsible for a higher mortality rate in Black breast cancer patients ( $<65$ years) which explains the one-third and one-fifth of the racial disparity, consecutively. In the U.S., Black women are 3 times less insured than White women, as found by studies [47]. In most cases, they use Medicaid insurance, a federal and state program for low-income people like minorities to cover their medical costs. A recent study using the entries of women served by Medicaid insurance at the state level points out that Black women receive lower mammography compared to White women in 30 of the 44 states [48]. Another fact triggering this rate is the irregular screening behavior among Black and Hispanic women. Studies demonstrate that they are less likely to attend follow-up after an abnormal test results in a mammogram [49] [50] [51]. In an evidence-based study by Highfield, L., the underutilization of the screening method is supported as well [52]. The higher mortality rate in Hispanic and Black women can be explained further by saying that they are diagnosed with breast cancer at a more advanced stage than White women and as a result, they are less likely to get stage-specific treatment [28] [53].

Although breast cancer is not a preventable disease, it is possible to treat and increase the survival rate [20]. The U.S. preventive task force recommends that women within 50 - 74 yrs should take biennial mammogram screening [54]. However, the incidence rate is increasing in the $40-64$ yrs age group for Hispanic-Black women. On the other hand, mammogram screening shows poor sensitivity at young age [55]. Therefore, prevention is not only possible by lowering the screening age but focusing on other factors as well. This study demonstrates the possible and effective preventive measures for BC such as an insurance system devoid of racial disparity, routine check-ups, culturally adaptive health promotion program to clear misconceptions about surgery, educating the Black population about physical activity, considering the clinical characteristics of the population before starting chemoprevention, etc. Creating equal opportunities and easy availability of resources before the adverse, can help reduce the mortality rate. Interruptions caused due to culture can be curbed with the right amount of awareness in the form of education. Racial discrimination or the fear of it, can cause Hispanic black women to access adequate primary care or regular screening [56]. There is a decrease observed in the intake of HRT which was one of the reasons for the higher incidence rate in white Hispanic women along with lifestyle problems such as obesity. 5.4\% - 5.6\% of cases expected to occur in 2025 would be due to obesity if the current rate is maintained. If obesity were eradicated, the deaths due to breast cancer would reduce to 3300 - 5700 in the year 2025 in women above 25 years [57]. Promoting a healthy lifestyle and reduction in the supply of HRT for pre and post-menopause symptoms will not only help reduce $\mathrm{BC}$ but also other diseases. Substantial improvements in the U.S. breast 
cancer control can be made by ensuring that all women receive indicated systemic therapy, use regular screening, and avoid obesity after age 50 [57].

Previous demographic and retrospective studies are available with trend analysis from 1973 to 2013 which is not specific to any specific parameter such as, race, age, etc [58]. A recent retrospective study has also shown trend analysis on U.S. breast cancer data from 2000 to 2015, however, the analysis focused on incidence and survival of young adults (20 - 49 yrs) whereas mortality rate and older age group are substantially significant for breast cancer patients [26]. There is a significant gap in the understanding of previous trends of BC in the U.S., especially between the Black and White populations. The finding of this study demonstrates that significant disparities are in these two races. This present study reveals the correlation and comparison of breast cancer incidence and mortality rate between Black and White American women. It further investigates significant racial disparities and explores possible reasons behind this. This finding can postulate how the incidence and mortality rate can take shape in the future.

The death rate for breast cancer was equal before 1980 between Black and White American women [59]. Recent data shows that the scenario has changed. Proper change in oncologic infrastructure should come into the function for narrowing the disparity. Furthermore, young age groups can consider lifestyle changes as the mammogram is not effective for them. However, individual age groups should be studied thoroughly and compared to see which factors are affecting each age group and how that can be eradicated.

The limitation of the study is the short period of time (2000-2016). Typically, time trend analysis explores a longer period so that the pattern of change can be well understood. The study would be more credible if the original number of population (sample in each cohort) could be extracted. Also, in certain age groups, the data showed fluctuating results, therefore, no concluding results were found. This study is a base for future analysis in breast cancer prevention. Further studies are needed focusing specifically on the breast cancer type and individual risk factors. Studies can also focus on the association of different socioeconomic and sociocultural factors with $\mathrm{BC}$ incidence and mortality in certain racial groups.

\section{Data Availability}

The data used in this trend analysis is available on the Surveillance, Epidemiology and End Results Program website at https://seer.cancer.gov/.

\section{Conflicts of Interest}

The authors declare no conflicts of interest regarding the publication of this paper.

\section{References}

[1] Torre, L.A., Bray, F., Siegel, R.L., Ferlay, J., Lortet-Tieulent, J. and Jemal, A. (2015) Global Cancer Statistics, 2012. CA: A Cancer Journal for Clinicians, 65, 87-108. 
https://doi.org/10.3322/caac.21262

[2] Goli, S., Moradhvaj, Chakravorty, S. and Rammohan, A. (2019) World Health Status 1950-2015: Converging or Diverging. PLoS ONE, 14, e0213139.

https://doi.org/10.1371/journal.pone.0213139

[3] Makki, J. (2015) Diversity of Breast Carcinoma: Histological Subtypes and Clinical Relevance. Clinical Medicine Insights. Pathology, 8, 23-31. https://doi.org/10.4137\%2FCPath.S31563

[4] CDC (Centers for Disease Control and Prevention) (2019) U.S. Cancer Statistics: Highlights from 2017 Incidence.

https://www.cdc.gov/cancer/uscs/about/data-briefs/no8-USCS-highlights-2016-inci dence.htm

[5] Breastcancer.org (2021) U.S. Breast Cancer Statistics. https://www.breastcancer.org/symptoms/understand bc/statistics

[6] Noone, A.M., Cronin, K.A., Altekruse, S.F., Howlader, N., Lewis, D.R., Petkov, V.I., et al. (2017) Cancer Incidence and Survival Trends by Subtype Using Data from the Surveillance Epidemiology and End Results Program, 1992-2013. Cancer Epidemiology, Biomarkers \& Prevention, 26, 632-641. https://doi.org/10.1158/1055-9965.EPI-16-0520

[7] NIH (National Institutes of Health) (n.d.) Female Breast Cancer-Cancer Stat Facts. https://seer.cancer.gov/statfacts/html/breast.html

[8] Winters, S., Martin, C., Murphy, D. and Shokar, N.K. (2017) Breast Cancer Epidemiology, Prevention, and Screening. Progress in Molecular Biology and Translational Science, 151, 1-32. https://doi.org/10.1016/bs.pmbts.2017.07.002

[9] Komen.org (2020) Types of Breast Tumors.

https://www.komen.org/breast-cancer/diagnosis/factors-that-affect-prognosis/tumo r-types/

[10] Lakhani, S.R., Ellis, I.O., Schnitt, S.J., Tan, P.H. and van de Vijver, M.J. (Eds.) (2012) WHO Classification of Tumours of the Breast. 4th Edition, Vol. 4, World Health Organization, International Agency for Research on Cancer, Lyon.

[11] Tamir, C., Budiman, A., Noe-Bustamante, L. and Mora, L. (2021) Facts about the U.S. Black Population. Pew Research Center.

https://www.pewresearch.org/social-trends/fact-sheet/facts-about-the-us-black-pop ulation/

[12] DeSantis, C.E., Fedewa, S.A., Sauer, G.A., Kramer, J.L., Smith, R.A. and Jemal, A. (2016) Breast Cancer Statistics, 2015: Convergence of Incidence Rates between Black and White Women. CA: A Cancer Journal for Clinicians, 66, 31-42.

https://doi.org/10.3322/caac.21320

[13] DeSantis, C., Siegel, R., Bandi, P. and Jemal, A. (2011) Breast Cancer Statistics, 2011. CA: A Cancer Journal for Clinicians, 61, 408-418. https://doi.org/10.3322/caac.20134

[14] DeSantis, C.E., Ma, J., Gaudet, M.M., Newman, L.A., Miller, K.D., Sauer, A.G., et al. (2019) Breast Cancer Statistics, 2019. CA: A Cancer Journal for Clinicians, 69, 438-451. https://doi.org/10.3322/caac.21583

[15] Yedjou, C.G., Sims, J.N., Miele, L., Sims, J.N., Miele, L., Noubissi, F., et al. (2019) Health and Racial Disparity in Breast Cancer. In: Ahmad, A., Ed., Breast Cancer Metastasis and Drug Resistance, Vol. 1152, Springer, Cham, 31-49. https://doi.org/10.1007/978-3-030-20301-6 3

[16] National Cancer Institute (2016) Cancer Disparities. 
https://www.cancer.gov/about-cancer/understanding/disparities

[17] Bradley, C.J., Given, C.W. and Roberts, C. (2001) Disparities in Cancer Diagnosis and Survival. Cancer, 91, 178-188.

https://doi.org/10.1002/1097-0142(20010101)91:1\%3C178::AID-CNCR23\%3E3.0.C $\underline{\mathrm{O} ; 2-\mathrm{S}}$

[18] Hegarty, V., Burchett, B.M., Gold, D.T. and Cohen, H.J. (2000) Racial Differences in Use of Cancer Prevention Services among Older Americans. Journal of the American Geriatrics Society, 48, 735-740. https://doi.org/10.1111/j.1532-5415.2000.tb04746.x

[19] International Agency for Research on Cancer (2013) Latest World Cancer Statistics Global Cancer Burden Rises to 14.1 Million New Cases in 2012: Marked Increase in Breast Cancers Must Be Addressed. Press Release, No. 223, International Agency for Research on Cancer, Lyon.

[20] Sun, Y.S., Zhao, Z., Yang, Z.N., Xu, F., Lu, H.J., Zhu, Z.Y., et al. (2017) Risk Factors and Preventions of Breast Cancer. International Journal of Biological Sciences, 13, 1387-1397. https://doi.org/10.7150/ijbs.21635

[21] Siegel, R.L., Miller, K.D. and Jemal, A. (2017) Cancer Statistics, 2017. CA: A Cancer Journal for Clinicians, 67, 7-30. https://doi.org/10.3322/caac.21387

[22] National Cancer Institute (2020) Breast Cancer Risk in American Women. https://www.cancer.gov/types/breast/risk-fact-sheet

[23] DePinho, R.A. (2000) The Age of Cancer. Nature, 408, 248-254. https://doi.org/10.1038/35041694

[24] Tomasetti, C. and Vogelstein, B. (2015) Variation in Cancer Risk among Tissues Can Be Explained by the Number of Stem Cell Divisions. Science, 347, 78-81. https://doi.org/10.1126/science.1260825

[25] Burkhalter, M.D., Rudolph, K.L. and Sperka, T. (2015) Genome Instability of Ageing Stem Cells-Induction and Defence Mechanisms. Ageing Research Reviews, 23, 29-36. https://doi.org/10.1016/j.arr.2015.01.004

[26] Thomas, A., Rhoads, A., Pinkerton, E., Schroeder, M.C., Conway, K.M., Hundley, W.G., et al. (2019) Incidence and Survival among Young Women With Stage I-III Breast Cancer: SEER 2000-2015. JNCI Cancer Spectrum, 3, Article No. pkz040. https://doi.org/10.1093/jncics/pkz040

[27] National Cancer Institute (2019) Overview of the SEER Program. SEER Explorer. https://seer.cancer.gov/about/overview.html\#: :text=The

[28] Richardson, L.C., Henley, S.J., Miller, J.W., Massetti, G. and Thomas, C.C. (2016) Patterns and Trends in Age-Specific Black-White Differences in Breast Cancer Incidence and Mortality-United States, 1999-2014. Morbidity and Mortality Weekly Report, 65, 1093-1098. https://doi.org/10.15585/mmwr.mm6540a1

[29] Chlebowski, R.T., Chen, Z., Anderson, G.L., Rohan, T., Aragaki, A., Lane, D., et al. (2005) Ethnicity and Breast Cancer: Factors Influencing Differences in Incidence and Outcome. Journal of the National Cancer Institute, 97, 439-447.

https://doi.org/10.1093/jnci/dji064

[30] American Cancer Society (2019) Breast Cancer Facts \& Figures 2019-2020. American Cancer Society, Inc., Atlanta.

https://www.cancer.org/content/dam/cancer-org/research/cancer-facts-and-statistic s/breast-cancer-facts-and-figures/breast-cancer-facts-and-figures-2019-2020.pdf

[31] American Cancer Society (2019) Cancer Facts \& Figures for African Americans. https://www.cancer.org/research/cancer-facts-statistics/cancer-facts-figures-for-afri 
can-americans.html

[32] Warner, E.T., Tamimi, R.M., Boggs, D.A., Rosner, B., Rosenberg, L., Colditz, G.A., et al. (2013) Estrogen Receptor Positive Tumors: Do Reproductive Factors Explain Differences in Incidence between Black and White Women? Cancer Causes \& Control, 24, 731-739. https://doi.org/10.1007/s10552-013-0153-9

[33] Haiman, C.A., Pike, M.C., Bernstein, L., Jaque, S.V., Stanczyk, F.Z., Afghani, A., et al. (2002) Ethnic Differences in Ovulatory Function in Nulliparous Women. British Journal of Cancer, 86, 367-371. https://doi.org/10.1038/sj.bjc.6600098

[34] Wu, T., Mendola, P. and Buck, G.M. (2002) Ethnic Differences in the Presence of Secondary Sex Characteristics and Menarche among U.S. Girls: The Third National Health and Nutrition Examination Survey, 1988-1994. Pediatrics, 110, 752-757. https://doi.org/10.1542/peds.110.4.752

[35] Zujewski, J.A., Dvaladze, A.L., Ilbawi, A., Anderson, B.O., Luciani, S., Stevens, L., et al. (2018) Knowledge Summaries for Comprehensive Breast Cancer Control. Journal of Global Oncology, 4, 1-7. https://doi.org/10.1200/JGO.17.00141

[36] Anderson, S.E., Dallal, G.E. and Must, A. (2003) Relative Weight and Race Influence Average Age at Menarche: Results from Two Nationally Representative Surveys of U.S. Girls Studied 25 Years Apart. Pediatrics, 111, 844-850. https://doi.org/10.1542/peds.111.4.844

[37] Brett, K.M. and Chong, Y. (2001) Hormone Replacement Therapy-Knowledge and Use in the United States. National Center for Health Statistics, Hyattsville. https://www.cdc.gov/nchs/data/misc/hrt booklet.pdf

[38] Gerend, M.A. and Manacy, P. (2008) Social Determinants of Black-White Disparities in Breast Cancer Mortality: A Review. Cancer Epidemiology, Biomarkers \& Prevention, 17, 2913-2923. https://doi.org/10.1158/1055-9965.EPI-07-0633

[39] Sung, H., Siegel, R.L, Rosenberg, P.S. and Jemal, A. (2019) Emerging Cancer Trends among Young Adults in the USA: Analysis of a Population-Based Cancer Registry. Lancet Public Health, 4, E137-E147. https://doi.org/10.1016/S2468-2667(18)30267-6

[40] Clarke, C.A., Glaser, S.L., Uratsu, C.S., Selby, J.V., Kushi, L.H. and Herrinton, L.J. (2006) Recent Declines in Hormone Therapy Utilization and Breast Cancer Incidence: Clinical and Population-Based Evidence. Journal of Clinical Oncology, 24, e49-e50. https://doi.org/10.1200/JCO.2006.08.6504

[41] Stang, A. (2008) Decline in Hormone Replacement Prescription and Fall in Breast Cancer Incidence-An Epidemiologic Discussion. Deutsches Ärzteblatt International, 105, 303-309. https://doi.org/10.3238/arztebl.2008.0303

[42] American Cancer Society (2019) Cancer Facts \& Figures for African Americans 2019-2021. American Cancer Society, Atlanta.

https://www.cancer.org/content/dam/cancer-org/research/cancer-facts-and-statistic s/cancer-facts-and-figures-for-african-americans/cancer-facts-and-figures-for-afric an-americans-2019-2021.pdf

[43] Huo, D., Hu, H., Rhie, S.K., Gamazon, E.R., Cherniack, A.D., Liu, J., et al. (2017) Comparison of Breast Cancer Molecular Features and Survival by African and European Ancestry in the Cancer Genome Atlas. JAMA Oncology, 3, 1654-1662. https://doi.org/10.1001/jamaoncol.2017.0595

[44] Hance, K.W., Anderson, W.F., Devesa, S.S., Young, H.A. and Levine, P.H. (2005) Trends in Inflammatory Breast Carcinoma Incidence and Survival: The Surveillance, Epidemiology, and End Results Program at the National Cancer Institute. Journal of the National Cancer Institute, 97, 966-975. 
https://doi.org/10.1093/jnci/dji172

[45] Cleaveland Clinic (2018) Breast Cancer: Causes, Stage, Diagnosis \& Treatment. https://my.clevelandclinic.org/health/diseases/3986-breast-cancer

[46] Williams, D.R., Mohammed, S.A. and Shields, A.E. (2016) Understanding and Effectively Addressing Breast Cancer in African American Women: Unpacking the Social Context. Cancer, 122, 2138-2149. https://doi.org/10.1002/cncr.29935

[47] Jemal, A., Robbins, A.S., Lin, C.C., Flanders, W.D., DeSantis, C.E., Ward, E.M., et al. (2018) Factors that Contributed to Black-White Disparities in Survival among Nonelderly Women with Breast Cancer between 2004 and 2013. Journal of Clinical Oncology, 36, 14-24. https://doi.org/10.1200/JCO.2017.73.7932

[48] Tangka, F.K., Subramanian, S., Mobley, L.R, Hoover, S., Wang, J., Hall, I.J., et al. (2017) Racial and Ethnic Disparities among State Medicaid Programs for Breast Cancer Screening. Preventive Medicine, 102, 59-64.

https://doi.org/10.1016/j.ypmed.2017.06.024

[49] Chang, S.W., Kerlikowske, K., Nápoles-Springer, A., Posner, S.F., Sickles, E.A. and Pérez-Stable, E.J. (1996) Racial Differences in Timeliness of Follow-Up after Abnormal Screening Mammography. Cancer, 78, 1395-1402. https://doi.org/10.1002/(SICI)1097-0142(19961001)78:7\%3C1395::AID-CNCR5\%3E 3.0.CO;2-K

[50] Adams, S.A., Smith, E.R., Hardin, J., Prabhu-Das, I., Fulton, J. and Hebert, J.R. (2009) Racial Differences in Follow-Up of Abnormal Mammography Findings among Economically Disadvantaged Women. Cancer, 115, 5788-5797. https://doi.org/10.1002/cncr.24633

[51] Rauscher, G.H., Allgood, K.L., Whitman, S. and Conant, E. (2012) Disparities in Screening Mammography Services by Race/Ethnicity and Health Insurance. Journal of Women's Health, 21, 154-160. https://doi.org/10.1089/jwh.2010.2415

[52] Highfield, L., Bartholomew, L.K., Hartman, M.A., Ford, M.M. and Balihe, P. (2014) Grounding Evidence-Based Approaches to Cancer Prevention in the Community: A Case Study of Mammography Barriers in Underserved African American Women. Health Promotion Practice, 15, 904-914. https://doi.org/10.1177\%2F1524839914534685

[53] Brawley, O.W. (2013) Health Disparities in Breast Cancer. Obstetrics and Gynecology Clinics of North America, 40, 513-523.

https://doi.org/10.1016/j.ogc.2013.06.001

[54] United States Preventive Services Taskforce (2016) Recommendation: Breast Cancer: Screening.

https://uspreventiveservicestaskforce.org/uspstf/recommendation/breast-cancer-scr eening

[55] Young Survival Coalition. Breast Cancer Statistics in Young Adults. https://www.youngsurvival.org/learn/about-breast-cancer/statistics

[56] Silber, J.H., Rosenbaum, P.R., Clark, A.S., Giantonio, B.J., Ross, R.N., Teng, Y., et al. (2013) Characteristics Associated With Differences in Survival among Black and White Women with Breast Cancer. Journal of the American Medical Association, 310, 389-397. https://doi.org/10.1001/jama.2013.8272

[57] Mandelblatt, J., van Ravesteyn, N., Schechter, C., Chang, Y., Huang, A.-T., Near, A.M., et al. (2013) Which Strategies Reduce Breast Cancer Mortality Most? Collaborative Modeling of Optimal Screening, Treatment, and Obesity Prevention. Cancer, 119, 2541-2548. https://doi.org/10.1002/cncr.28087 
[58] Verdial, F.C., Etzioni, R., Duggan, C. and Anderson, B.O. (2017) Demographic Changes in Breast Cancer Incidence, Stage at Diagnosis and Age Associated with Population-Based Mammographic Screening. Journal of Surgical Oncology, 115, 517-522. https://doi.org/10.1002/jso.24579

[59] McDowell, S. (2017) Study: Lack of Insurance Linked to Higher Breast Cancer Death Rates in Black Women.

https://www.cancer.org/latest-news/study-lack-of-insurance-linked-to-higher-breas t-cancer-death-rates-in-black-women.html 